\title{
SOCIAL VARIETY IN THE YELLOW-BELLIED MARMOT: A POPULATION-BEHAVIOURAL SYSTEM
}

\author{
BY KENNETH B. ARMITAGE \\ Rocky Mountain Biological Laboratory, Colorado and Division of Biological Sciences, University of \\ Kansas, Lawrence, Kansas 66045
}

\begin{abstract}
Rates of amicable and agonistic behaviour are not correlated either within or between two colonies of Marmota flaviventris nor is there any consistent pattern of rates being higher in one colony than in the other. Rates of social behaviour are related to population density, the age-sex structure of the population, the individual behavioural characteristics of the residents and potential recruits, the way in which space is shared, and the number of years residents have lived together.
\end{abstract}

The social and population biology of the yellow-bellied marmot (Marmota flaviventris) have been intensively studied (Armitage 1962, 1965, 1973, 1974; Downhower \& Armitage 1971; Armitage \& Downhower 1974). These studies revealed considerable variation in social behaviour which has been incorporated into a model of population regulation (Armitage 1975). Furthermore, each marmot has a behavioural profile which affects not only its relationship with other marmots but also the spatial distribution and population dynamics of marmots (Svendsen 1974).

Barash (1973a, 1974) suggested that social behaviour of marmots is closely related to those ecological variables correlated with length of growing season. Yellow-bellied marmots living at $3850 \mathrm{~m}$ were smaller and more sociable than those living at $2650 \mathrm{~m}$. However, Armitage, Downhower \& Svendsen (1976) found no difference in body weights of marmots living at 2900 and $3400 \mathrm{~m}$ when weights were compared at the same time in the annual cycle. Furthermore, my studies reveal wide variation in behaviour from year to year in the same colony and in the same year among colonies at the same elevation. The purpose of this paper is to describe the nature of this behavioural variety.

\section{Methods}

The marmot colonies chosen for detailed analysis are located in the East River Valley, Colorado, at an elevation of $2900 \mathrm{~m}$. The precise location of the colonies, habitat descriptions, methods of handling, marking, and observation, and delineation of home ranges were detailed elsewhere (Armitage 1973, 1974, 1975). Observations were concentrated between 06.00 and 10.00 and 16.00 and 19.00 hours (M.S.T.) when marmots are most active (Armitage 1962).
The data reported herein were obtained from 1962 to 1971 , inclusive. Each year observation began about 5 June and concluded about 15 August. However, in 3 years observations began as early as 8 May and concluded when animals hibernated in mid-September or early October.

All social behaviour was recorded directly into a field notebook and later categorized as amicable or agonistic. Amicable behaviour includes greeting and mutual or allogrooming; agonistic behaviour includes alert, flight and chase. Descriptions of these behaviour patterns and the rationale for categorizing them as amicable or agonistic were presented elsewhere (Armitage 1973, 1974). Briefly, amicable behaviour patterns are those that bond; $66 \%$ of amicable behaviour patterns were greetings. Agonistic behaviour patterns repel other members of the population; $78 \%$ of agonistic behaviour patterns were flights or chases. Marmots were classified as juveniles (young in their first summer of life), yearlings (animals in their second summer of life) and adults (all animals in their third summer of life or older). Rates of agonistic and amicable behaviour, mean number of residents, and the distribution of social interactions among selected age-sex groups were plotted against time (Figs 1 and 2). Juvenile behaviour is excluded from this report for two reasons. First, social behaviour among juveniles and between juveniles and older animals is predominantly amicable so that rates of amicable behaviour are unduly influenced by the number of young present, which may be zero in some years. Second, juvenile behaviour is difficult to compare between colonies because much of the juvenile behaviour at colony 5 occurred behind dense vegetation which made obtaining accurate rates impossible and the 
inclusion of those rates would bias comparisons between colonies. Social behaviour among adult males is not shown because it is rare and is related to territoriality (Armitage 1974). Social interactions among yearlings are not shown in the age-sex interaction triangles because such behaviour occurred in less than half the years of observation and accounted for only $15.5 \%$ of all social interactions. However, the plot of mean rates in Figs 1 and 2 includes social interactions among yearlings.

Rates of amicable and of agonistic behaviour between colonies and between years within colonies were tested for statistical significance by the Mann-Whitney $U$-test (Siegel 1956, p. 116). The $t$-test to compare means was not used because the assumptions of this test; e.g. normal distribution, could not be met. The results of the Mann-Whitney $U$-test should be treated with caution as $U$ may be strongly affected by the distribution of the scores. One unusually high score in a population of low scores may increase $U$ and therefore the probability that all scores are from the same population even though one mean may be twice the other. By contrast, all the scores from one population may be slightly lower than all the scores from the other population. The statistic $U$ will be low and the probability that the scores are from the same population will be low even though the means differ by about $20 \%$. In the first case, the observer will opt for biological significance; in the second case biological significance will be strongly suspect.

\section{Results \\ Within Colony Variation \\ River colony (locality 1). Rates of social behaviour, the number of residents, the number of female yearlings and adults, and patterns of social interactions among age-sex groups varied from year to year (Fig. 1). Furthermore, changes}

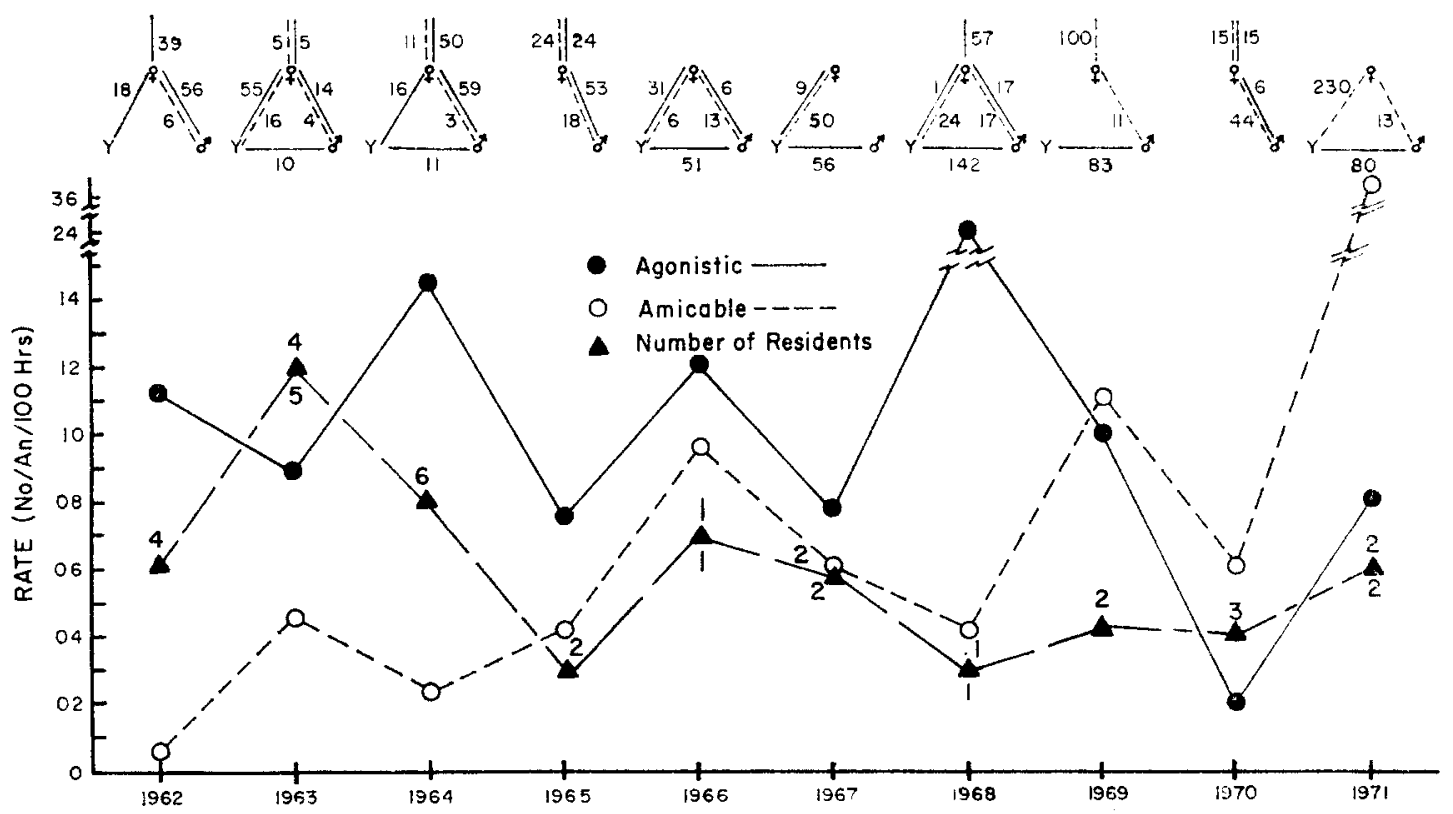

Fig. 1. River colony (locality 1). Mean rates of agonistic and of amicable behaviour and mean number of residents for all age-sex groups. The number above each solid triangle is the number of female adults and the number below each solid triangle is the number of female yearlings who were resident throughout the summer for each year. The rates among three age-sex groups are shown as interaction triangles across the top of the figure. The vertical line above $q$ refers to interactions among adult $O$ 's. The numbers are rate values calculated for $1000 \mathrm{~h} . Y=$ yearlings, both sexes; solid line = agonistic behaviour; dotted line = amicable behaviour. 
in amicable and/or agonistic behaviour from one year to the next are not proportional among the age-sex groups.

In 1962, four females and two males formed two polygynous groups (Downhower \& Armitage 1971). Half of the agonistic behaviour was between adult males and adult females. All behaviour among females was agonistic; the yearlings emigrated.

Agonistic behaviour significantly declined and amicable behaviour significantly increased in 1963 (Fig. 3). These changes were associated with the return of all the adults who were present in 1962. The decline in agonistic behaviour occurred because it decreased among adults (Fig. 1). Agonistic behaviour between adults and yearlings was 3.5 times greater than in 1962. About $75 \%$ of the agonistic behaviour involved \$24 who was always dominant. Consequently, only one of the five female yearlings who remained throughout the summer had a home range which overlapped that of $\$ 24$. The increase in amicable behaviour resulted primarily from yearling-female : adult-female behaviour.
All adult females, except $\$ 24$, participated. Only yearling 917 had no amicable relationships with adults and was the yearling participant in $62 \%$ of the yearling-female : adultfemale agonistic behaviour.

In 1964 only one adult female present in 1963 returned. Four adult females were yearlings in 1963; the sixth adult, 991 , was new. Two new adult males were present. The significant increase in agonistic behaviour (Fig. 3) was associated with the high rate of adult-male : adult-female conflict and the ten-fold increase in agonistic behaviour among adult females. The dominant 991 participated in $70 \%$ of the agonistic behaviour among adult females. Her home range was in the centre of the locality and overlapped the home ranges of all other females, except 917 , who occupied a dominant position on the south side of the locality. All behaviour toward yearlings was agonistic; all yearlings emigrated.

The population decrease in 1965 was associated with an increase in amicable and a decrease in agonistic behaviour. Social interactions
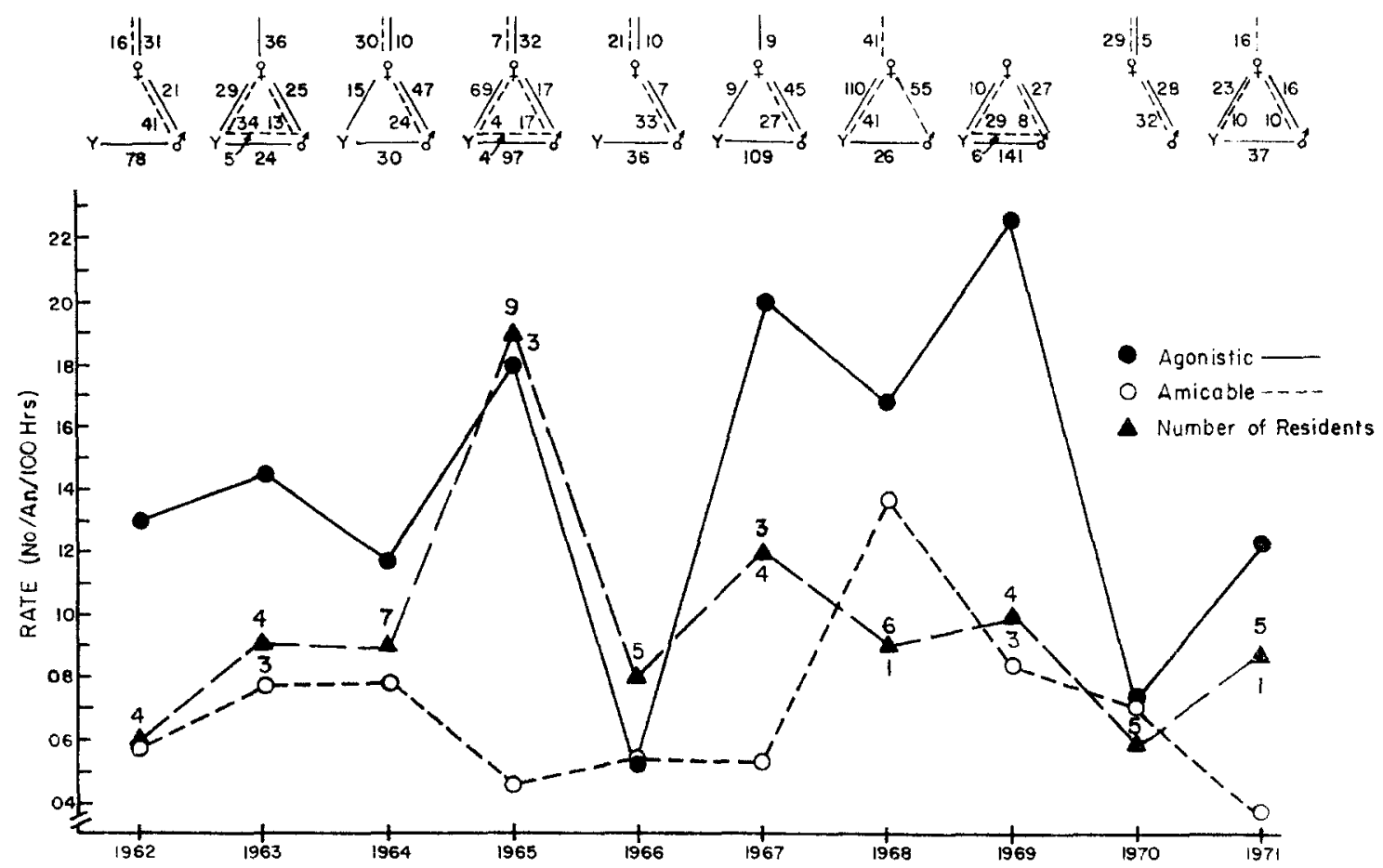

Fig. 2. Picnic colony (locality 5). Mean rates of agonistic and of amicable behaviour and mean number of residents for all age-sex groups for the entire colony. All symbols and values as in Fig. 1. 
between the adult females and the adult male remained high as a new male replaced the two of 1964. Dominant 917 died in a trap accident; \$366 and 95 extended their home ranges into the area previously used by 917 . The two females thereby avoided $\$ 91$ with whom they had agonistic conflicts in 1964. The reduction in agonistic behaviour among adult females occurred because of the avoidance of $\$ 91$; the increase in amicable behaviour resulted from contacts between 's 366 and 5 associated with their home range overlap.

Only o366 was resident in 1966. Although the increase in agonistic behaviour was not statistically significant, its distribution among age-sex groups changed from a pattern of adult : adult conflict in 1965 to one of adult : yearling conflict in 1966 (Fig. 1). Three of the four male yearlings and one of the two female yearlings emigrated by July 19 . The resident female

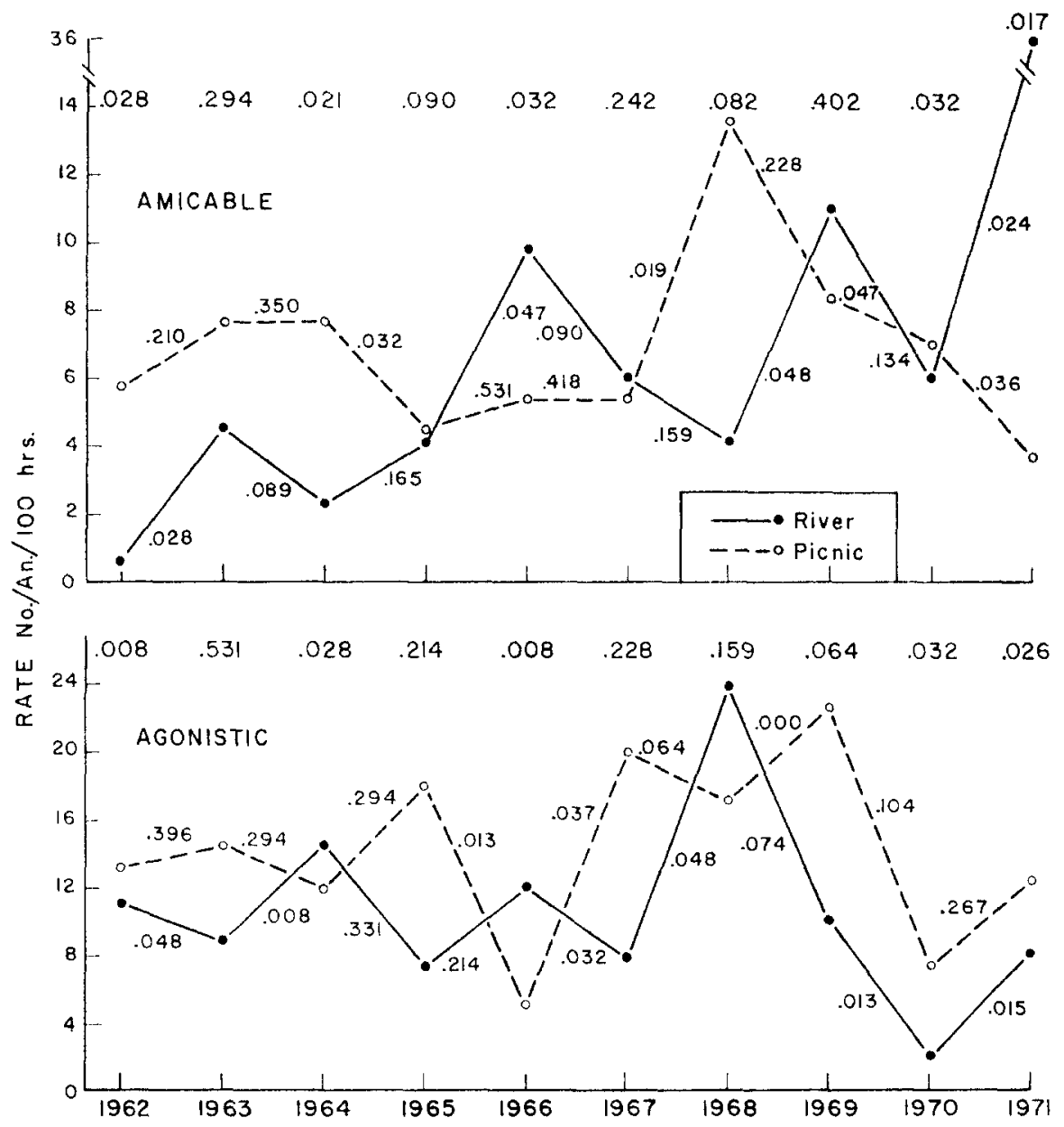

Fig. 3. Comparison of mean rates of agonistic and of amicable behaviour between River colony and Picnic colony. The probabilities (calculated from Mann-Whitney $U$-test) that there are no differences between mean rates are recorded as follows. The numbers across the top of each graph are probabilities comparing mean rates between colonies. Numbers above the dashed lines are probabilities comparing mean rates from one year to the next for Picnic colony. Numbers under the solid line are probabilities comparing mean rates from one year to the next for River colony. 
yearling established a home range independent of that of 9366 . The significant increase in amicable behaviour occurred because of a high rate of yearling : yearling interactions.

The significant decrease in agonistic behaviour in 1967 occurred because of the change in the pattern of yearling-female : adult-female interactions. Agonistic behaviour between these agesex groups was less than one-third the rate of 1966; amicable behaviour increased eight-fold. Only $\$ 366$ had social interactions with the female yearlings who were her daughters. The home ranges of the three animals were virtually identical. There were no social interactions between the two adult females; their home ranges were discrete. The agonistic behaviour of the adult male was directed at two male yearlings who emigrated.

Neither of the adult females of 1967 returned in 1968. The two yearling females of 1967 were pressent as adults along with three female and one male yearling. In mid-June $\$ 649$ moved into the colony from nearby colony 2 (Armitage 1973). Agonistic behaviour significantly increased to the highest recorded at this locality. Agonistic behaviour among adult females was also the highest recorded. Eighty per cent of the adult-male : yearling agonistic behaviour was with the male yearling. The two adult females and three yearlings dispersed. Female 685 , who was classified behaviourally as an avoider (Svendsen \& Armitage 1973) lived nearby as a satellite. One female yearling lived at the northwestern edge of the locality where she avoided contact with $\$ 649$. The yearling subsequently emigrated to a satellite site.

The events of 1968 were surprising as 9649 was not particularly aggressive (Armitage 1973). Probably she could not have driven out the other females if they had not been essentially submissive behavioural types and yearlings (all yearlings are subordinate to adults). Her lack of aggressiveness was supported by the behavioural patterns of 1969. Amicable behaviour significantly increased because of the amicable relationships between $\$ 649$ and new $\$ 1146$ which were the highest recorded among adult females (Fig. 1). Greetings and allogrooming often were initiated by the 7-year-old $q 649$. All agonistic behaviour was directed by the male toward transient yearlings all of whom dispersed by July 2 .

Agonistic behaviour declined to its lowest level in 1970 (Fig. 3). These low rates were associated with a lack of yearlings and with only slight overlap in the home ranges of the resident females, one of whom was the submissive $\$ 685$ who returned from living as a satellite. Although amicable behaviour declined, the rate between the adult male and the females was the highest recorded at this locality. Two of the adult females and the male were newly resident.

The significant increase in agonistic behaviour in 1971 resulted from conflict between the adult male and a yearling male. Of the three females present in 1970, 9685 reverted to satellite status and $9 \mathrm{~s} 728$ and 789 , categorized as sociable (Svendsen \& Armitage 1973), returned to the same non-overlapping home ranges they occupied in 1970 . Consequently, there were no social interactions among adult females. Amicable behaviour significantly increased to the highest level recorded in this colony (Fig. 3) and occurred mainly between $\$ 728$ and the three yearlings who were her offspring. The yearlings were categorized as avoiders.

Picnic colony (locality 5). The situation at locality 5 is more complex because the number of harems varied from one to three. Social interactions between members of different harems varied from year to year and yearlings often were not clearly associated with a particular harem. In some years, amicable or agonistic behaviour was observed only in one of the harems; therefore, in some instances, it will be necessary to treat each harem separately.

As in River colony, population numbers and structure, rates of social behaviour, and patterns of social interactions among age-sex groups varied from year to year. Changes in rates of amicable and/or agonistic behaviour from one year to the next are not proportional among the age-sex groups (Fig. 2).

In 1962, all social interactions among females occurred in the lower harem and their rate of agonistic behaviour was the highest measured in the 10-year period. Forty per cent of their home ranges were shared in common; by contrast, the overlap of home ranges among the non-agonistic females in the upper harem was $75 \%$. The high level of agonistic behaviour between an adult male and a yearling was associated with the yearling's dispersal.

Although neither agonistic nor amicable behaviour changed significantly in 1963, the age-sex distribution of these behaviours changed (Fig. 2). Social interactions between female yearlings and female adults predominated. 
Three of five female yearlings became residents.

There was no significant change in rates of either amicable or agonistic behaviour in 1964, but the distribution of the behaviours among the age-sex groups changed. The increase in amicable and decrease in agonistic behaviour among adult females was associated with an increase in the number of resident females to seven (Fig. 2), five of these females were resident as adults or yearlings in 1963. Their home ranges overlapped by $97 \%$, the largest recorded in the lower harem. Only agonistic behaviour occurred between the male yearling and adults; the yearling dispersed.

The significant decrease in amicable behaviour in 1965 was associated with a decrease in this behaviour among adult females. All of the amicable behaviour among adult females occurred in the lower harem where a new female became resident. Although the $50 \%$ increase in the rate of agonistic behaviour was not statistically significant, major shifts in its distribution occurred. Agonistic behaviour among adult females increased three-fold and was limited to females in the upper harem. Two temporarily resident females emigrated and $\$ 643$ emerged as a dominant, aggressive animal. Agonistic behaviour between yearlings and adults increased ten-fold and accounted for $70 \%$ of all agonistic behaviour. Ninetythree per cent of the home ranges of the three female resident yearlings was within the home ranges of the adult females of the lower harem. Five male yearlings remained; $48 \%$ of their home ranges lay inside the home range of the adult male. The large number of male yearlings and the high rate of adult-male : yearling-male agonistic behaviour probably occurred because the single male was unable to defend his unusually large territory, an area usually partitioned between two males (Armitage 1974).

The decline in the number of residents in 1966 was associated with a significant decline in agonistic behaviour to the lowest value measured in this colony. This low level occurred because of a decrease in agonistic behaviour between adults and yearlings. There were no female yearlings and male yearlings dispersed early. All behaviour among adult females occurred in the lower harem. The rate of amicable behaviour was three times that of agonistic behaviour; the adult females were all returnees from 1965 . Only aggressive $\$ 643$ remained in the upper harem.
The significant increase of agonistic behaviour in 1967 occurred primarily as a result of increased activity by the resident males. There was one adult female in each of three harems. Yearling $\$ 530$ associated with the 5 year old 9643 in the upper harem; two female yearlings lived with a subordinate female in the middle harem, and two female and three male yearlings lived with a new adult female in the lower harem. Only yearling $\$ 683$ and the new female in the lower harem evidenced agonistic behaviour. The lower harem male was shot in mid June; subsequently the remaining two harem males made excursions to the lower harem where they had social interactions with the adult female and the five yearlings. The residency of the male yearlings was attributed to the lack of a resident adult male (Armitage 1974).

The number of adult female residents increased in 1968, although the mean number of residents declined as only one yearling was resident. Both $\$ 530$ and $q 683$ lived in the same areas they occupied the previous year. A new female shared the upper harem with ${ }^{5} 530$; although their home ranges overlapped by $80 \%$, no social interactions were observed between them. The significant increase in amicable behaviour occurred because of the amicable interactions of the two returning females of the lower harem and the amicable interactions between the yearling female and adult female of the middle harem. The decline in agonistic behaviour was attributed primarily to the lack of agonistic interactions between adult males and adult females.

The mean number of residents in 1969 was similar to that of 1968 , but the age structure changed markedly. Only one adult male was present, there was a decline in the number of adult females and an increase in the number of yearling females, and two male yearlings were resident. The significant increase in agonistic behaviour was attributed to the activity of the male (Fig. 2) whose aggression was directed primarily toward the male yearlings. Amicable behaviour in 1969 was $60 \%$ of that of 1968 . The decline occurred primarily among adults. Amicable behaviour among yealings was 55\% of the total amicable behaviour. This unusually high social activity among yearlings resulted in no significant difference in amicable behaviour between colonies (Fig. 3). No social interactions were observed among the adult females, all of whom were returnees. 
Both amicable and agonistic behaviour declined significantly in 1970 (Fig. 3) as did the mean number of residents (Fig. 2). These declines coincided with an absence of yearlings. All of the social interactions among females occurred between 9683 and three 2-year-olds who were her daughters.

Amicable behaviour declined significantly in 1971 to the lowest level measured in this colony. Only amicable behaviour occurred among the resident adult females who were returness from 1970 . The behavioural profiles of $\$ 683$ and one 3-year-old were categorized as sociable and those of the other two 3-yearolds were classified as avoiders (also highly subordinate) (Svendsen \& Armitage 1973). The yearling female was categorized as aggressive. She was resident despite being chased by $\$ 683$. However, only $56 \%$ of her home range overlapped that of 9683 . A male yearling dispersed.

\section{Comparison Between Colonies}

Amicable behaviour of colony 5 was greater than that of colony 1 in 1962,1964, 1965, and 1968 (Fig. 3). Rates of amicable behaviour of colony 1 exceeded those of colony 5 in 1966 , 1970 , and 1971. For the three remaining years, differences were not significant $(P>0 \cdot 242)$. Rates of agonistic behaviour of colony 1 exceed those of colony 5 in 1964 and 1966. Rates of agonistic behaviour of colony 5 exceeded those of colony 1 in 1962,1969, 1970, and 1971 (Fig. 3). There were no significant differences in rates of agonistic behaviour for the remaining 4 years $(P>0 \cdot 159)$.

Further possible relationships between the year-to-year patterns of social behaviour and population density were tested by Spearman rank correlation (Siegel 1956, p. 202). Amicable behaviour, agonistic behaviour, and population density were ranked from high to low for each colony. The rank order of each was compared between the two colonies. There were no significant correlations (amicable behaviour, $r_{\mathrm{s}}=$ -0.248 ; agonistic behaviour, $r_{\mathrm{s}}=-0.115$; population density, $r_{\mathrm{s}}=-0.13$; all $P>0.05$ ). Furthermore, year-to-year changes in amicable and agonistic behaviour within colonies were not correlated (colony $1, r_{\mathrm{s}}=-0.26, P>0.05$; colony $\left.5, r_{\mathrm{s}}=-0.14, P>0.05\right)$.

\section{Discussion}

Clearly the year-to-year patterns of social behaviour and population changes vary between the two colonies of marmots. Which colony has higher rates of amicable or agonistic behaviour in any year depends on the prevailing factors affecting social behaviour in that particular year. The lack of any correlation between colonies in the rates of social behaviour suggests there is no factor integrating the behaviour-population systems of these two colonies $4.3 \mathrm{~km}$ and less than $100 \mathrm{~m}$ elevation apart. Each colony must be treated essentially as a separate system.

Several general characteristics of the behavioural-population system are apparent from the detailed descriptions of the two colonies. When the population in a given year consists primarily of adults who were resident the previous year, there is a marked decline in agonistic behaviour; amicable behaviour may increase (Fig. 1, River 1963; Fig. 2, Picnic $1964,1966,1968,1971)$. By contrast, the presence of immigrants is associated with increased agonistic and decreased amicable behaviour (Fig. 1, River 1964; Fig. 2, Picnic 1965). Presumably social integration of residents occurs which results in an overall decrease in amicable and agonistic behaviour.

A similar pattern occurs in adult-male : adultfemale behaviour. In 1964,1965 , and 1970 when a new male became resident at colony 1 , rates of social interactions were high (Fig. 1). Conversely, in 1963, 1966 to 1969 , and 1971, when the resident male returned from the previous year, rates of social interactions were low (Armitage 1974).

Social behaviour varies with population changes. For example, population decreases were associated with an increase in amicable behaviour and a decrease in agonistic behaviour (River 1965; Picnic 1966, 1970). Population increases were associated with increased agonistic and/or decreased amicable behaviour (River 1966; Picnic 1965, 1967). However, there is no consistent relationship between population density and rates of social behaviour (Armitage \& Downhower 1974; Armitage 1975). Population density is affected by environmental factors such as burrow sites and food resources which vary among the places marmots live (Svendsen 1974). More importantly high rates of social behaviour may occur because of the activity of one particular animal (River 1968, 1969; Picnic 1965) which results in high rates of social behaviour being associated with a low population density. Furthermore, emigration reduces conflict. Agonistic behaviour between yearlings and adults may be high in June but then drop to zero because yearlings disperse (e.g. River 
1967; Picnic 1964). Furthermore, density effects are strongly affected by the behavioural types of the residents (River 1971; Picnic 1971).

Rates of social behaviour are related to the use of space. The habitat may be partitioned among adult females so that little or no social behaviour occurs among them (e.g. River 1967, 1971; Picnic 1969). High rates of agonistic behaviour occur when the home range of one or more dominant females overlaps the home ranges of other females (River 1964; Picnic 1962). Sociable females may have overlapping home ranges and high rates of amicable behaviour (River 1965; Picnic 1964) or no social interactions (Picnic 1962, 1968).

Rates of social behaviour are affected by the age-sex structure of the population (River 1966, 1970; Picnic 1963, 1965, 1967, 1969). Social behaviour between yearlings and adults determines whether yearlings disperse or are recruited into the colony (Armitage \& Downhower 1974; Armitage 1975). The considerable year-to-year variation in adult-yearling social behaviour is dependent partly on the sex of the yearlings. Virtually all male yearlings disperse; if dispersal is delayed, agonistic behaviour between the adult male and the yearling males is high (Armitage 1974). Adultfemale : yearling-male behaviour generally is agonistic; the presence of yearling males reduces overall amicable behaviour and increases overall agonistic behaviour.

The social behaviour between female yearlings and adults is more complex. Although the adult male may be agonistic toward female yearlings, this behaviour seems to be sexual-aggressive; no instance of female yearling dispersal is attributable to male aggression. By contrast, female adults have chased female yearlings from their natal colony. Residency of female yearlings usually is associated with high amicable and/or low agonistic behaviour between adult and yearling females (River 1967, 1971; Picnic 1967, 1969). Furthermore, the relationship is complicated by female yearlings using parts of the habitat not used by adults (e.g. River 1966, 1968; Picnic 1971) and thereby avoiding social interactions. Yearling females may be recruited into the population even though agonistic rates are high if one or more adult females is sociable. More than $70 \%$ of the home ranges of the yearlings overlapped those of the sociable adults (e.g. River 1963; Picnic 1965). In summary, the pattern of use of space, sex of the yearlings, and behavioural characteristics of the females determine rates of social interactions between yearling and adult age-sex groups.

Barash (1974) suggested that the social biology of marmots may be adjusted to local ecology. This hypothesis is best supported by differences in interspecific social organization in which the age of dispersal of $M . \operatorname{monax}, M$. flaviventris, and $M$. olympus is juvenile, yearling, and 2-year-old, respectively. Barash (1973a, 1974) attributed these differences to the length of the growing season and suggested that growth rates are slower at the higher elevations. His suggestions were tested in a yellow-bellied marmot colony at $3400 \mathrm{~m}$ altitude where the number of days that marmots gained weight were virtually identical to the number of days M. olympus gained weight (Barash 1973b). The growth rates of juvenile $M$. flaviventris at $3400 \mathrm{~m}$ were significantly greater than those of juveniles at $2900 \mathrm{~m}$ (Andersen, Armitage \& Hoffman 1976). Thus the hypothesis of a necessary relationship between length of growing season, reduced growth rates, and social biology is not supported.

Barash (1974) also suggested that adjustments to local ecology occurred intraspecifically. This hypothesis was supported by a 1-year study of social behaviour of two colonies of yellowbellied marmots. The high elevation colony had higher rates of amicable and lower rates of agonistic behaviour than a colony at lower elevations (Barash 1973a). However, the analysis of social behaviour of yellow-bellied marmots over 10 years reveals that rates of social behaviour are associated with population density, the age-sex structure of the population, whether animals have lived together previously, the way in which space is shared, and the individual behavioural characteristics of the residents and potential recruits. The differences Barash reporported could result from any combination of the factors reported here. Elsewhere I have attempted to incorporate these factors into a population dynamics model (Armitage 1975). For purposes of this discussion, the model emphasizes that the social system is inseparable from the population system. Any hypotheses of the role of environment as a modifier of social behaviour must be formulated in the context of the behaviour-population system. Only studies of the same colonies for several years can reveal consistent behavioural differences independent of population fluctuations with their concomitant changes in age-sex structure. Otherwise, any suggestions that growing season, food 
resources, burrow sites, or other environmental parameters modify intraspecific social behaviour in consistent ways are premature.

\section{Acknowledgments}

These studies were supported by N.S.F. grants G 16354, GB 6123, GB 1980, GB 8526 and GB 32494. Field assistance was provided by M. S. Topping, J. F. Downhower, D. R. Michener, G. L. Worthen, D. L. Kilgore, Jr, R. R. Fleet, and G. E. Svendsen. Ann Schlager and Mary Makepeace prepared the figures. I wish to thank D. P. Barash for helpful comments on an early draft of the manuscript.

\section{R E F E R E N C ES}

Andersen, D. C., Armitage, K. B. \& Hoffmann, R. S. 1976. Socio-ecology of marmots: female reproductive strategies. Ecology, 57, 552-560.

Armitage, K. B. 1962. Social behaviour of a colony of the yellow-bellied marmot (Marmota faviventris). Anim. Behav., 10, 319-331.

Armitage, K. B. 1965. Vernal behaviour of the yellowbellied marmot (Marmota faviventris). Anim. Behav., 13, 59-68.

Armitage, K. B. 1973. Population changes and social behavior following colonization by the yellowbellied marmot. J. Mammal., 54, 842-854.
Armitage, K. B. 1974. Male behaviour and territoriality in the yellow-bellied marmot. J. Zool., Lond., 192, 233-265.

Armitage, K. B. 1975. Social behavior and population dynamics of marmots. Oikos, 26, 341-354.

Armitage, K. B. \& Downhower, J. F. 1974. Demography of yellow-bellied marmot populations. Ecology, 55, 1233-1245.

Armitage, K. B., Downhower, J. F. \& Svendsen, G. E. 1976. Seasonal changes in weights of marmots. Am. Midl. Nat., 96, 36-51.

Barash, D. P. 1973a. Social variety in the yellow-bellied marmot (Marmota flaviventris). Anim. Behav., 21, 579-584.

Barash, D. P. 1973b. The social biology of the Olympic marmot. Anim. Behav. Monogr., 6, 171-245.

Barash, D. P. 1974. The evolution of marmot societies: a general theory. Science, N.Y., 185, 415-420.

Downhower, J. F. \& Armitage, K. B. 1971. The yellowbellied marmot and the evolution of polygamy. Amer. Nat., 105, 355-370.

Siegel, S. 1956. Non-parametric Statistics. New York: McGraw-Hill.

Svendsen, G. E. 1974. Behavioral and environmental factors in the spatial distribution and population dynamics of a yellow-bellied marmot population. Ecology, 55, 760-771.

Svendsen, G. E. \& Armitage, K. B. 1973. Mirror-image stimulation applied to field behavioral studies. Ecology, 54, 623-627.

(Received 8 April 1975; revised 12 November 1975; MS. number: A1699) 